\title{
Patient satisfaction with the cervical ripening balloon as a method for induction of labour: a randomised controlled trial
}

\author{
Sheri Ee-lin $\underline{\mathrm{Lim}}^{1}$, PhD, MRCOG, Toh Lick $\underline{\mathrm{Tan}}^{1,2}$, MBBS, MRCOG, Grace Yang Huang $\underline{\mathrm{Ng}}^{1}$, MBChB, \\ Shephali $\underline{\text { Tagore }}^{3}$, MBBS, MRCOG, Ei Ei Phyo $\underline{K y a w}^{3}$, BDS, BSc(Hons), George Seow Heong $\underline{\text { Yeo }}^{3}$, FRCOG, FAMS
}

INTRODUCTION Evidence has shown that balloon catheters are as effective as prostaglandins (PGE) in achieving vaginal delivery within 24 hours of the start of induction of labour ( $\mathrm{IOL}$ ), with lower rates of uterine hyperstimulation, and similar Caesarean section and infection rates. International guidelines recommend mechanical methods as a method of IOL. We designed a prospective randomised controlled study to evaluate patient acceptance of the cervical ripening balloon (CRB) for IOL.

METHODS Suitable women with a singleton term pregnancy without major fetal anomaly suitable for vaginal delivery were recruited and randomised to receive the CRB or PGE on the day of IOL. Characteristics of the women, labour and birth outcomes were obtained from case notes. Pain and satisfaction scores were obtained by interviewing the women at IOL and after delivery. The main outcome measures were participant characteristics, labour and birth outcomes, pain score, satisfaction scores, and whether the participant would recommend the mode of IOL.

RESULTS There was no difference in the pain score between the two groups at the start of IOL, but thereafter, pain scores were lower in the CRB group compared to the PGE group $(4.5 \pm 2.3$ vs. $5.6 \pm 2.4, p=0.044)$. Women were equally satisfied with both methods and equally likely to recommend their method for IOL.

CONCLUSION Patient experience of IOL with CRB or PGE was equally satisfactory, although pain during induction was lower in the CRB group. We found that both methods of IOL are acceptable to women and should be made available to provide more options.

Keywords: acceptability, cervical ripening, Cook balloon, labour induction, mechanical ripening

\section{INTRODUCTION}

The frequency of induction of labour (IOL) has dramatically risen in the last decade. Approximately one in five deliveries in the United Kingdom and United States are induced, making it a very common intervention for pregnant women. ${ }^{(1,2)}$ Prostaglandins (PGE) have long replaced traditional mechanical methods as the mainstay of cervical ripening to induce labour. The National Institute for Health and Care Excellence guidelines for $\mathrm{IOL}^{(2)}$ recommend the use of vaginal PGE as the preferred method of induction and state that mechanical methods, including balloon catheters and laminaria tents, should not be routinely used. However, since the publication of these guidelines more than a decade ago, mechanical methods have been recommended by the American Congress of Obstetricians and Gynecologists, ${ }^{(1)}$ World Health Organization ${ }^{(3)}$ and Canada ${ }^{(4)}$ IOL guidelines. This international resurgence comes after the Cochrane review on mechanical methods for $\mathrm{IOL}^{(5)}$ which found that mechanical methods were as effective as PGE in achieving vaginal delivery within 24 hours of the start of the intervention, with lower risk of uterine hyperstimulation. Similar Caesarean section and infection rates were also found. Other advantages of mechanical methods are their stability at room temperature and relatively easy insertion.
However, little information is available about women's acceptance of balloon devices for IOL. In our department in a maternity teaching hospital in Singapore, $\mathrm{IOL}$ is carried out using PGE as the standard of care. We designed a randomised controlled study to evaluate the use of a cervical ripening balloon (CRB) compared to PGE to assess patient satisfaction with Prostin (Pfizer, New York City, NY, USA) and the Cook ${ }^{\circledR}$ Cervical Ripening Balloon (Cook Medical, Bloomington, IN, USA) in the local Singapore population. Our choice of the double balloon catheter was based on the hypothesis that it would be as effective as PGE in achieving vaginal delivery. Patient acceptance of this alternative method would allow clinicians and patients to tailor individual care. We have also found in an unpublished study that trainees with no previous experience could rapidly achieve competency in insertion of the CRB when training is supplemented by lectures, simulation and supervision, which supports the implementation of the CRB as an alternative IOL method.

\section{METHODS}

This study was carried out from 2014 to 2015 at KK Women's and Children's Hospital, Singapore. Pregnant women aged 21-40 years old at term $(37+0$ weeks to $41+6$ weeks $)$ with a

${ }^{1}$ Department of Obstetrics and Gynaecology, KK Women's and Children's Hospital, ${ }^{2}$ Thomson Women's Clinic, 'Department of Maternal Fetal Medicine, KK Women's and Children's Hospital, Singapore

Correspondence: Dr Sheri Ee-lin Lim, Senior Resident, Department of Obstetrics and Gynaecology, KK Women's and Children's Hospital, 100 Bukit Timah Road, Singapore 229899. sheri.lim@mohh.com.sg 


\begin{tabular}{|l|c|c|c|c|c|c|c|c|c|c|c|}
\hline Pain score & $\begin{array}{c}\text { No } \\
\text { pain }\end{array}$ & 1 & \multicolumn{2}{|c|}{$\begin{array}{c}\text { Like having IV } \\
\text { access }\end{array}$} & 5 & 6 & \multicolumn{3}{|c|}{ Like labour pain } & 10 \\
\hline At induction & 0 & 1 & 2 & 3 & 4 & 5 & 6 & 7 & 8 & 9 & 10 \\
\hline Post induction & 0 & 1 & 2 & 3 & 4 & 5 & 6 & 7 & 8 & 9 & 10 \\
\hline $\begin{array}{l}\text { Maternal satisfaction } \\
\text { overall score }\end{array}$ & $0-1-2-3-4-5$ & & $\begin{array}{c}\text { Would } \\
\text { recommend to } \\
\text { other women }\end{array}$ & Yes & No \\
\hline Comments & $0-1-3$ & \\
\hline
\end{tabular}

Fig. 1 Chart shows the form that was used to collect information from patients regarding maternal satisfaction.

singleton pregnancy who were suitable for a vaginal delivery were invited to join the study. Pregnancies with major fetal anomaly or scarred uterus were excluded. Women were randomised to either the CRB or PGE arm. Identical envelopes were prepared, each containing a folded paper; 75 envelopes had the words 'Cervical Ripening Balloon' and another 75 had the word 'Prostin'. The envelopes were shuffled and sealed. They were then labelled sequentially with an allocation number from 1 to 150. Recruited participants were allocated to the next random allocation number in sequence. After recruitment, the women were checked to ensure that their cervical dilatation was less than $3 \mathrm{~cm}$, membranes were still intact, presentation was cephalic and cardiotocography (CTG) was normal. Those who withdrew from the study were excluded. The detailed methodology has been described in a previous published study. ${ }^{(6)}$

Identification of eligible pregnant women occurred in the antenatal outpatient clinic after the woman received antenatal counselling by her attending doctor, or in labour ward triage. A member of the research team explained the study and obtained consent if the woman was agreeable. It was stressed that the study was voluntary and did not affect her medical care and the woman was free to withdraw from the study without prejudice. Women who needed time to consider joining the study were followed up the next day or at the next antenatal visit. A patient information leaflet on IOL, with information on the study, members of the team and their contact details, was made available to the patient. The cost of CRB and PGE induction was comparable. On average, the CRB was slightly cheaper (CRB SGD 200 vs. PGE SGD 228), as $47 \%$ women receiving PGE required more than one dose given 6-8 hours apart, necessitating more blocks of time on labour ward as per our hospital's protocol for IOL.

On the day of IOL, the patient was reviewed by one of the study doctors to ensure patient eligibility. A presentation scan, vaginal examination for cervical dilatation and CTG were performed before IOL was initiated. Women who had placement of the CRB were examined abdominally and vaginally. The perineum and vagina were cleaned using antiseptic solution. The CRB was introduced into the endocervix by direct visualisation. The uterine and vaginal balloon reservoirs were gradually inflated at approximately one, two and three hours after insertion of the CRB until there was $80 \mathrm{~mL}$ in each balloon. CTG monitoring was carried out for more than 20 minutes before and after insertion of the CRB and inflation of the double balloon catheter. If the woman was not in labour after inflation of the balloons, she was transferred to the antenatal ward to ambulate, then sent to the labour ward for removal of the CRB 12 hours later, or when spontaneous expulsion of the catheter or rupture of the membranes occurred.

Women who were randomised to the PGE arm had placement of $3 \mathrm{mg}$ of Prostin (dinoprostone vaginal tablets) intravaginally. The patient was asked to remain recumbent for 30 minutes. Fetal heart and uterine activity was monitored continuously for at least two hours before the patient was transferred to the antenatal ward to ambulate, provided that the CTG was satisfactory and the patient was not in labour. If there was inadequate response, a further dose of Prostin was given six hours later in the labour ward. Amniotomy and/or syntocinon infusion was given as necessary. If amniotomy was not possible after two doses of PGE or after the CRB was removed, the induction was deemed as a failed IOL. The patient would then leave the study and the attending doctor would take over her subsequent management. This usually included a further dose of PGE.

After delivery, a member of the study team interviewed the patients. Information collected included patients' views on pain felt during the induction process, overall satisfaction, comments and whether they would recommend their mode of induction to other women (Fig. 1). No patients were lost to follow-up, as we were able to follow up on all recruited patients within a few days of delivery. Characteristics of labour and birth outcomes were obtained from medical case notes.

Normally distributed data was presented as mean \pm standard deviation, and $\mathrm{p}$-values were calculated using Student's $t$-test. For categorical data, p-values were calculated with Pearson's chi-square or Fisher's exact tests. A p-value of 0.05 was used as the cut-point for significance. This data was collected, collated and analysed using IBM SPSS Statistics version 19.0 (Armonk, NY, USA). The study was approved by the SingHealth Centralised Institutional Review Board (reference number 2013/553/D).

\section{RESULTS}

A total of 138 women were approached to join the study, but 40 women declined. Hence, a total of 98 women were enrolled. 
Table I. Characteristics of participants undergoing cervical ripening balloon (CRB) and prostaglandin (PGE) induction of labour (IOL).

\begin{tabular}{|c|c|c|c|}
\hline \multirow[t]{2}{*}{ Parameter } & \multicolumn{2}{|c|}{ No. $(\%) /$ mean \pm SD } & \multirow[t]{2}{*}{ p-value } \\
\hline & CRB $(n=31)$ & PGE $(n=52)$ & \\
\hline Maternal age (yr) & $28.2 \pm 5.3$ & $28.7 \pm 5.0$ & 0.646 \\
\hline Ethnicity $^{\dagger}$ & & & 0.222 \\
\hline Chinese & $11(35.5)$ & $22(42.3)$ & \\
\hline Malay & $17(54.8)$ & $19(36.5)$ & \\
\hline Indian & $1(3.2)$ & $8(15.4)$ & \\
\hline Others & $2(6.5)$ & $3(5.8)$ & \\
\hline Primigravidae $^{\dagger}$ & $19(61.3)$ & $23(44.2)$ & 0.174 \\
\hline Weight* (kg) & $64.4 \pm 15.0$ & $63.9 \pm 13.2$ & 0.861 \\
\hline$B M I *\left(k g / m^{2}\right)$ & $25.5 \pm 5.0$ & $25.0 \pm 5.1$ & 0.706 \\
\hline Predelivery Hb* $(g / d L)(n=80)$ & $11.6 \pm 1.8$ & $12.0 \pm 1.3$ & 0.211 \\
\hline GBS positive $^{\dagger}(n=79)$ & $7(22.6)$ & $11(21.2)$ & 0.204 \\
\hline Gestational age* (wk) & $39.4 \pm 1.1$ & $39.2 \pm 1.9$ & 0.357 \\
\hline Cervical dilatation* $(\mathrm{cm})$ & $1.0 \pm 0.7$ & $0.9 \pm 0.7$ & 0.954 \\
\hline Primary indication for $\mathrm{IOL}^{+}$ & & & 0.108 \\
\hline Decreased fetal movement ${ }^{\ddagger}$ & - & $6(11.5)$ & 0.082 \\
\hline Postdate ${ }^{\ddagger}$ & $17(54.8)$ & $17(32.7)$ & 0.065 \\
\hline Gestational diabetes $^{\ddagger}$ & $5(16.1)$ & $7(13.5)$ & 0.756 \\
\hline Impending macrosomia ${ }^{\ddagger}$ & - & $1(1.9)$ & 0.526 \\
\hline IUGR ${ }^{\ddagger}$ & $1(3.2)$ & - & 0.137 \\
\hline Low amniotic fluid index ${ }^{\ddagger}$ & $6(19.4)$ & $18(34.6)$ & 0.089 \\
\hline Maternal request ${ }^{\ddagger}$ & $1(3.2)$ & $3(5.8)$ & 0.489 \\
\hline Preeclampsia $^{\ddagger}$ & $1(3.2)$ & - & 0.373 \\
\hline
\end{tabular}

Value of $\mathrm{n}$ is stated when missing data was excluded from analysis. ${ }^{*} \mathrm{p}$-value was calculated with Student's $t$-test, + Pearson's chi-square test, $¥$ Fisher's exact test. GBS: Group B streptococcus; Hb: haemoglobin; IUGR: intrauterine growth restriction; SD: standard deviation

14 women were excluded from analysis: seven went into spontaneous labour before their IOL, two were found to have non-cephalic fetal presentation, one had confirmed rupture of membranes prior to $\mathrm{IOL}$, one was found to have a gestation less than $37+0$ weeks, and three women presented for IOL when the research team was unavailable. One woman randomised to the CRB arm withdrew from the study after 8 hours 55 minutes due to discomfort from the balloon catheter. The remaining 83 cases were analysed and their characteristics are shown in Table I.

There was no significant difference between the characteristics of the women in the CRB and PGE arms in terms of maternal age $(28.2 \pm 5.3$ years vs. $28.7 \pm 5.0$ years; $p=0.646)$, ethnicity $(p=0.222)$, proportion of primigravidae $(61.3 \%$ vs. $44.2 \% ; p=0.174)$, weight $(64.4 \pm 15.0 \mathrm{~kg}$ vs. $63.9 \pm 13.2 \mathrm{~kg}$; $\mathrm{p}=0.861), \operatorname{BMl}\left(25.5 \pm 5.0 \mathrm{~kg} / \mathrm{m}^{2}\right.$ vs. $\left.25.0 \pm 5.1 \mathrm{~kg} / \mathrm{m}^{2} ; \mathrm{p}=0.706\right)$, gestational age $(39.4 \pm 1.1$ weeks vs. $39.2 \pm 1.9$ weeks; $p=0.357)$ and primary indication for IOL $(\mathrm{p}=0.108)$.

Induction to vaginal delivery time and vaginal delivery rate were similar in both arms of the study (Table II). ${ }^{(7)}$ Compared to the PGE arm, participants undergoing CRB IOL achieved active labour in a shorter span of time and were more likely to require oxytocin infusion for augmentation, as uterine contractions at the time of artificial rupture of membranes were less frequent. One case of uterine hyperstimulation was found in the PGE arm, although this was not clinically significant. The patient progressed rapidly from $4 \mathrm{~cm}$ to full dilatation within 40 minutes, and achieved a normal vaginal delivery. The baby's Apgar scores were 9 at one minute and five minutes. No case of uterine rupture was observed. The birth outcomes of both arms of the study were also similar, with no case of stillbirth (Table III). There were two cases of neonatal intensive care unit admission in the PGE arm for continuous positive airway pressure therapy. Both were discharged from the neonatal intensive care unit within 24 hours.

The pain scores at the start of IOL were similar. However, the pain score in the CRB group was significantly lower than in the PGE group during the induction process $(4.5 \pm 2.3$ vs. $5.6 \pm 2.4$; $\mathrm{p}=0.044)$ (Table IV). Epidural rates were similar in the two groups. Nevertheless, both groups expressed good satisfaction scores (CRB $3.4 \pm 1.5$ vs. PGE $3.2 \pm 1.4 ; p=0.465)$, and the majority of the women said they would recommend their method of IOL (CRB 71.0\% vs. PGE 69.2\%; $p=1.000$ ) (Table IV). As part of the pro forma, patients were asked to comment on their IOL experience post delivery. 22 free-text comments were recorded, with an equal number of comments from each arm. Comments from the PGE arm were related to speed, pain and effectiveness, in descending order. Four out of 11 comments from this arm were complaints that the induction process took too long. The majority (five out of 11) of comments from the CRB group were mainly related to discomfort (including the patient who withdrew from the study due to discomfort) regarding the catheter tube strapped to the leg or pressure from the balloon catheter. Two women would still recommend this method of IOL to other women, and 
Table II. Labour outcomes of participants undergoing cervical ripening balloon (CRB) and prostaglandin (PGE) induction of labour (IOL).

\begin{tabular}{|c|c|c|c|}
\hline \multirow[t]{2}{*}{ Parameter } & \multicolumn{2}{|c|}{ No. $(\%) /$ mean \pm SD } & \multirow[t]{2}{*}{ p-value } \\
\hline & CRB $(n=31)$ & PGE $(n=52)$ & \\
\hline IOL to $\geq 4 \mathrm{~cm}$ dilatation* $(\mathrm{hr})(\mathrm{n}=78)$ & $14.4 \pm 5.7$ & $23.5 \pm 16.6$ & $0.001^{\S}$ \\
\hline IOL to full dilatation* $(h r)(n=66)$ & $20.8 \pm 6.1$ & $24.8 \pm 15.7$ & 0.150 \\
\hline IOL to vaginal delivery* $(h r)(n=63)$ & $21.2 \pm 6.8$ & $25.6 \pm 16.1$ & 0.136 \\
\hline Duration of $2 n d$ stage* $(h r)(n=63)$ & $0.9 \pm 2.9$ & $0.8 \pm 0.9$ & 0.741 \\
\hline Delivery within 24 hr $^{\dagger}$ & $17(54.8)$ & $25(48.1)$ & 0.265 \\
\hline Failed IOL & $1(3.2)$ & $9(17.3)$ & 0.082 \\
\hline No. of PGE used ${ }^{\dagger}$ & & & $<0.001$ \\
\hline 0 & $30(96.8)$ & - & \\
\hline 1 & $1(3.2)$ & $28(53.8)$ & \\
\hline 2 & - & $15(28.8)$ & \\
\hline 3 & - & $9(17.3)$ & \\
\hline Augmentation use ${ }^{\ddagger}$ & $24(77.4)$ & $26(50.0)$ & $0.020^{\S}$ \\
\hline Epidural use ${ }^{\ddagger}$ & $18(58.1)$ & $29(55.8)$ & 1.000 \\
\hline IOL to epidural use* $(\mathrm{hr})(\mathrm{n}=47)$ & $16.4 \pm 5.4$ & $23.2 \pm 15.8$ & $0.040^{\S}$ \\
\hline Epidural use to delivery* $(\mathrm{hr})(\mathrm{n}=47)$ & $9.2 \pm 4.1$ & $7.0 \pm 3.8$ & 0.065 \\
\hline \multicolumn{4}{|l|}{ Contractions* } \\
\hline At IOL & $0.2 \pm 0.6$ & $0.2 \pm 0.5$ & 0.579 \\
\hline $3 \mathrm{hr}$ after IOL $(\mathrm{n}=81)$ & $2.0 \pm 1.9$ & $1.6 \pm 1.9$ & 0.451 \\
\hline \multicolumn{4}{|l|}{ Contractions $>5$ every $10 \mathrm{~min}^{\neq}$} \\
\hline 30 min after IOL $(n=81)$ & - & - & - \\
\hline $3 \mathrm{hr}$ after $\mathrm{IOL}(\mathrm{n}=81)$ & - & $1(2.0)$ & 1.000 \\
\hline Vaginal delivery $^{\ddagger}$ & $22(71.0)$ & $41(78.8)$ & 0.438 \\
\hline Indication for $\operatorname{LSCS}^{\dagger}(n=20)$ & & & 0.513 \\
\hline Failed IOL & - & $2(18.2)$ & \\
\hline FTP in 1st stage of labour & $5(55.6)$ & $4(36.4)$ & \\
\hline FTP in 2nd stage of labour & $2(22.2)$ & $1(9.1)$ & \\
\hline NRFS & $1(11.1)$ & $3(27.3)$ & \\
\hline FTP and NRFS & $1(11.1)$ & $1(9.1)$ & \\
\hline
\end{tabular}

Value of $\mathrm{n}$ is stated when missing data was excluded from analysis. * $\mathrm{p}$-value was calculated with Student's $t$-test, + Pearson's chi-square test, $\neq F$ isher's exact test. $\S p$-value is statistically significant. FTP: failure to progress; NRFS: non-reassuring fetal status; SD: standard deviation

Table III. Birth outcomes of cervical ripening balloon (CRB) and prostaglandin (PGE) induction of labour (IOL).

\begin{tabular}{|c|c|c|c|}
\hline \multirow[t]{2}{*}{ Parameter } & \multicolumn{2}{|c|}{ No. $(\%) /$ mean \pm SD } & \multirow[t]{2}{*}{ p-value } \\
\hline & CRB $(n=31)$ & PGE $(n=52)$ & \\
\hline Male fetus ${ }^{\dagger}$ & $16(51.6)$ & $22(42.3)$ & 0.496 \\
\hline Birth weight* $(g)$ & $3,166 \pm 478$ & $3,094 \pm 417$ & 0.472 \\
\hline $\begin{array}{l}\text { Apgar score at } \\
5 \min <7\end{array}$ & - & - & - \\
\hline $\begin{array}{l}\text { Meconium } \\
\text { aspiration }\end{array}$ & - & - & - \\
\hline Pyrexia in labour ${ }^{+}$ & $2(6.5)$ & $3(5.8)$ & 1.000 \\
\hline NICU admission ${ }^{+}$ & - & $2(3.8)$ & 0.526 \\
\hline ICU admission & - & - & - \\
\hline
\end{tabular}

*p-value was calculated with Student's $t$-test, +Pearson's chi-square test, $\neq$ Fisher's exact test. ICU: intensive care unit; NICU: neonatal intensive care unit; SD: standard deviation

the other two would not. The patient who withdrew from the study was not included in the analysis and her comments were not recorded. Other comments in the CRB group pertained to pain
Table IV. Patient satisfaction with cervical ripening balloon (CRB) and prostaglandin (PGE) induction of labour (IOL).

\begin{tabular}{|llll|}
\hline Parameter & \multicolumn{2}{c}{ No. $(\%) /$ mean \pm SD } & p-value \\
\cline { 2 - 3 } & CRB $(\mathbf{n}=\mathbf{3 1})$ & PGE $(\mathbf{n}=\mathbf{5 2})$ & \\
\hline Pain score at $\mathrm{IOL}^{*}$ & $3.1 \pm 1.4$ & $2.6 \pm 1.9$ & 0.181 \\
\hline Pain score after IOL* & $4.5 \pm 2.3$ & $5.6 \pm 2.4$ & $0.044^{\ddagger}$ \\
\hline Satisfaction score* & $3.4 \pm 1.5$ & $3.2 \pm 1.4$ & 0.465 \\
\hline Would recommend $^{\dagger}$ & $22(71.0)$ & $36(69.2)$ & 1.000 \\
\hline
\end{tabular}

Pain was measured on a scale of $0-10$ and satisfaction on a scale of $0-5$. ${ }^{*}$-value was calculated with Student's $t$-test, +Pearson's chi-square test. $\neq p$-value is statistically significant. SD: standard deviation

$(n=2)$, perceived effectiveness ( $n=2$, one of whom achieved a normal vaginal delivery) and speed of the process $(n=1)$.

The patient who withdrew from the study was from the CRB group. Our records showed that insertion of the CRB was successful at the first attempt by a trained medical officer, taking five minutes and requiring no assistance. The CRB was in situ for 10 hours 55 minutes before the patient complained that the discomfort she felt was 'too unbearable'. The CRB was removed 
and the patient proceeded to have a PGE IOL. She received three doses of PGE and reached $3 \mathrm{~cm}$ cervical dilatation before artificial rupture of membranes and augmentation was carried out. The patient reached full dilatation but requested for an emergency Caesarean section, as she felt that her labour was taking too long. She delivered a female baby weighing 3,215 g with an Apgar score of 9 at one minute and five minutes. She was discharged well from hospital a few days later.

\section{DISCUSSION}

To the best of our knowledge, this is the first randomised controlled trial comparing acceptance of the CRB to that of PGE as an IOL method. The CRB was felt to be a less painful method of IOL as compared to PGE. In our local population, it was equally accepted and considered satisfactory. This study will serve as a platform to carry out more studies using the CRB, especially in higher-risk pregnancies and the outpatient setting.

The 2012 Cochrane review assessing the effects of mechanical methods of IOL was a landmark review endorsing the efficacy of mechanical methods in achieving delivery within 24 hours of the start of the intervention, with fewer episodes of uterine hyperstimulation compared to PGE. The study specifically reviewed a subgroup managed with transcervical Foley balloons, showing that the device was effective in increasing the favourability of the cervix compared to a placebo. ${ }^{(5)}$ Randomised controlled trials comparing single to double balloon catheters for IOL showed that they were equally efficacious. ${ }^{(7,8)}$ Double balloon catheters used in IOL have been found to result in fewer labour complications such as hyperstimulation and non-reassuring fetal heart patterns. ${ }^{(8)}$ Amid the emergence of new evidence on efficacy and safety in using mechanical methods for $\mathrm{OOL}$, especially in higher-risk pregnancies including oligohydramnios ${ }^{(9,10)}$ or scarred uteri, ${ }^{(5,11)}$ as well as their use in the outpatient setting, ${ }^{(12-15)}$ there is little data on women's acceptance of mechanical methods as an alternative for inducing labour.

Two publications have assessed women's acceptance of the balloon catheter for cervical ripening. Kehl et al explored the acceptability of a double balloon catheter used concomitantly with oral misoprostol. ${ }^{(16)}$ The double balloon catheter was accepted by the women and was found to have a positive impact on the birth experience. The trial found that women were not bothered by the placement of the device or the presence of the catheter. They reported that in a subsequent pregnancy, they would consider the methods they had tried and also recommend it to others. Cervical ripening with balloon catheters has been associated with significantly less pain than PGE, while single balloon catheters caused less pain than double balloon catheters (36\% vs. $55 \%$, pain score $\geq 4$ ). An Australian randomised pilot controlled study by Wilkinson et al ${ }^{(17)}$ compared inpatients' with outpatients' balloon catheter for cervical ripening. They found that most women reported some discomfort with insertion and wearing the catheter, but were equally satisfied with their care in both cases, felt that their baby was safe and felt less isolated when they were at home during the cervical ripening process. To the best of our knowledge, our study is the first to evaluate women's acceptance of the double balloon catheter compared to vaginal PGE as a method of IOL.

In assessing patient satisfaction with the CRB as a method of $I O L$, it was essential to assess the efficacy of the two methods, CRB and PGE. The results of our study were in keeping with the available evidence that mechanical methods are as efficacious as pharmacological methods in terms of induction to vaginal delivery time as well as vaginal delivery rates. Comparisons of patient characteristics, labour and birth outcomes were undertaken to identify any confounding factors that might have affected the experience of the women, and the maternal and neonatal outcomes were similar. In light of the similar efficacy of the CRB and PGE, it is possible to separate patient satisfaction from the outcome of delivery.

The pain score at the start of IOL was assessed to evaluate the pain during the insertion of the CRB compared to that with PGE. Interestingly, there was no difference in the pain score although the CRB, due to the nature of the product, required more time to insert than PGE, on average, and necessitated the use of a speculum. As more than one dose of PGE was often required before amniotomy was performed, it was not possible to compare the pain felt at the second PGE insertion as a distinct intervention. Instead, pain felt during the induction process was compared between the groups as a whole, and the pain felt during the induction process was significantly less in the CRB group. The onset of uterine contractions for PGE vaginal suppository is within 10 minutes and lasts up to $2-3$ hours. Women in the PGE group often required more than one dose $(46.1 \%)$ to bring about adequate cervical ripening and were subject to regular painful contractions and an additional vaginal examination for reinsertion of PGE that is likely to have affected their pain score.

The CRB group had significantly fewer regular contractions at the time of amniotomy compared to the PGE group despite similar successful vaginal delivery outcomes within 24 hours, suggesting that the CRB is efficacious while incurring less pain. The CRB required augmentation more often even though it enabled the group to reach cervical dilatation $>4 \mathrm{~cm}$ faster than the PGE group. The CRB ripens the cervix through direct pressure on the cervix while concomitantly stimulating endogenous PGE release, which aids in cervical ripening. The increase in local PGE leads to a series of complex changes within the cervix, including an increase in collagen degradation, hyaluronic acid, leucocyte chemotaxis and interleukin-8 release. These changes, coupled with uterine contractions, culminate in cervical effacement and dilatation. The level of endogenous PGE released as a result of the CRB may not be sufficient to bring about adequate uterine contractions within the period of induction of labour, thus requiring more augmentation compared to the PGE group.

Free-text comments from our patients included discomfort due to the catheter, but that did not affect the overall satisfaction score. It was noted that one patient from the CRB arm withdrew from the study, stating discomfort from the catheter as a reason. Her satisfaction score was therefore not included in the study's results, as she did not complete the induction. This case was interesting, as the patient received both methods of induction. 
We can postulate that her overall satisfaction score for CRB as a method of IOL would be low, but it was equally likely that she would be displeased with both methods of induction, as her induction with PGE also took a longer time and required three doses of PGE. If she had been included in the statistics, it is unlikely to have significantly affected the study outcome. Of note, $3 \mathrm{mg}$ PGE vaginal tablets are used as the standard method of IOL in our hospital (controlled-release dinoprostone vaginal pessary is not available). A patient who does not wish to continue using PGE has no recourse to withdraw, as PGE is not easily removed. Furthermore, the lack of an alternative $\mathrm{IOL}$ method means patients are likely to deliver by Caesarean section if they decline PGE. This further reinforces the need to evaluate a safe alternative method of IOL that is acceptable to patients.

A limitation of the study was the small sample size. Nevertheless, the sample size was similar to that of other studies that examined women's acceptance of the double balloon catheter as a method of IOL. Kehl's 2013 study $^{(16)}$ included an analysis of 79 questionnaires of women who were randomly assigned to a group that used oral misoprostol and a double balloon catheter, or to a control group that used oral misoprostol as a method for inducing labour. They similarly found that the double balloon catheter was accepted by the women and had a positive impact on the birth. Our pilot study contributes to the little information that is available about women's satisfaction with the CRB as a method of IOL. Completion of this pilot study also provided baseline information and prompted a subsequent larger prospective study of the CRB versus PGE, offering women in our hospital a choice of either method of IOL, which was previously not provided. The latter study was in progress at the time of publication and evaluated adverse events as well as patient satisfaction. Another limitation was that this pilot study was carried out in a single institution. Expansion of the study to other institutions with larger numbers would provide a better representation of women's satisfaction with the CRB as a method of IOL in Singapore.

Another limitation involves patient satisfaction, which is defined as a person's critical evaluation of an experience that is influenced by one's expectations, perceptions, attitudes and personal values. It is a valuable outcome measure for quality of care. ${ }^{(18)}$ Patient satisfaction is determined by the differences between what is expected and what actually happens. Although the study was randomised, the patient's personal background relating to the use of either method may influence the consideration of whether a method was efficacious or satisfactory. This is especially true for PGE: for instance, a patient may have a bad impression of PGE if her relative previously underwent IOL using PGE and had a bad experience. On the other hand, she may change her mind and evaluate PGE induction positively if her own delivery outcome is good. Similarly, the perception that CRB is a new method of $\mathrm{IOL}$ and not standard care may negatively influence another patient's perception of the induction process. In these scenarios, the patient's experience of IOL may be affected unless she is able to compare the two methods in her own obstetric history.
However, we attempted to minimise any bias towards either method of IOL. Patients were only recruited and uniformly counselled by a member of the study team. In addition, randomisation of patients to either group reduced the impact of any preconceptions as to which method was superior. Future studies may take into account previous induction methods that a patient has been exposed to and her acceptance of that IOL method.

In conclusion, this study explored the key clinical outcomes of efficacy and safety of the CRB as a method of IOL as well as the assessment of patient satisfaction in both groups, affirming previous positive findings in published data. The CRB was found to be equally acceptable when compared with PGE as a method of IOL among patients in a Singapore tertiary hospital setting.

\section{ACKNOWLEDGEMENT}

We are grateful for the CRBs provided by Cook Medical for the study.

\section{REFERENCES}

1. ACOG Committee on Practice Bulletins -- Obstetrics. ACOG Practice Bulletin No. 107: Induction of labor. Obstet Gynecol 2009; 114(2 Pt 1):386-97.

2. National Collaborating Centre for Women's and Children's Health (UK). Induction of Labour. NICE Clinical Guidelines, No. 70. London: RCOG Press, 2008.

3. World Health Organization. WHO recommendations for induction of labour. Available at: http://apps.who.int/iris/bitstream/10665/44531/1/9789241501156_ eng.pdf. Accessed June 26, 2018.

4. Induction of Labour. The Society of Obstetricians and Gynaecologists of Canada (SOGC) Clinical Practice Guideline No. 296, September 2013.

5. Jozwiak M, Bloemenkamp KW, Kelly AJ, et al. Mechanical methods for induction of labour. Cochrane Database Syst Rev 2012; CD001233.

6. Tan TL, Ng GY, Lim SE, et al. Cervical ripening balloon as an alternative for induction of labour: a randomized controlled trial. BJMP 2015; 8:a806.

7. Salim R, Zafran N, Nachum Z, et al. Single-balloon compared with doubleballoon catheters for induction of labor: a randomized controlled trial. Obstet Gynecol 2011; 118:79-86.

8. Pennell CE, Henderson JJ, O'Neill MJ, et al. Induction of labour in nulliparous women with an unfavourable cervix: a randomised controlled trial comparing double and single balloon catheters and PGE2 gel. BJOG 2009; 116:1443-52.

9. Wang W, Zheng J, Fu J, et al. Which is the safer method of labor induction for oligohydramnios women? Transcervical double balloon catheter or dinoprostone vaginal insert. J Matern Fetal Neonatal Med 2014; 27:1805-8.

10. Shechter-Maor G, Haran G, Sadeh-Mestechkin D, et al. Intra-vaginal prostaglandin E2 versus double-balloon catheter for labor induction in term oligohydramnios. J Perinatol 2015; 35:95-8.

11. Jozwiak M, Dodd JM. Methods of term labour induction for women with a previous caesarean section. Cochrane Database Syst Rev 2013; CD009792.

12. Dowswell T, Kelly AJ, Livio S, Norman JE, Alfirevic Z. Different methods for the induction of labour in outpatient settings. Cochrane Database Syst Rev 2010; CD007701.

13. Sciscione AC, Bedder CL, Hoffman MK, Ruhstaller K, Shlossman PA. The timing of adverse events with Foley catheter preinduction cervical ripening; implications for outpatient use. Am J Perinatol 2014; 31:781-6.

14. Sciscione AC, Muench M, Pollock M, et al. Transcervical Foley catheter for preinduction cervical ripening in an outpatient versus inpatient setting. Obstet Gynecol 2001; 98(5 Pt 1):751-6.

15. Henry A, Madan A, Reid R, et al. Outpatient Foley catheter versus inpatient prostaglandin E2 gel for induction of labour: a randomised trial. BMC Pregnancy Childbirth 2013; 13:25.

16. Kehl S, Welzel G, Ehard A, et al. Women's acceptance of a double-balloon device as an additional method for inducing labour. Eur J Obstet Gynecol Reprod Biol 2013; 168:30-5.

17. Wilkinson C, Adelson P, Turnbull D. A comparison of inpatient with outpatient balloon catheter cervical ripening: a pilot randomized controlled trial. BMC Pregnancy Childbirth 2015; 15:126.

18. Goodman P, Mackey MC, Tavakoli AS. Factors related to childbirth satisfaction. J Adv Nurs 2004; 46:212-9. 